\title{
Pengaplikasian Metode Stepping Stone Pada Sofware Lingo Untuk Mencari Optimasi Biaya (Studi Kasus di PT Asm Mobil)
}

\author{
The Application of Stepping Stone Method in Lingo Software for Optimizing Cost \\ (Case Study at PT Asm Mobil)
}

\author{
Hendriawan, Singgih Nugraha, Mochammad Fauzi \\ Program Studi Teknik Industri, Universitas Widyatama \\ E-mail: hendriaone19@gmail.com, SinggihN@gmail.com,muchammad.fauzi@widyatama.ac.id
}

\begin{abstract}
Abstrak
PT. Asm Mobil adalah perusahaan yang bergerak dalam jasa service dan penjualan material service kendaraan yang pada tahun 2019 menetapkan sistem insentif untuk meningkatkan produktivitas dari segi penjualan sehingga timbul masalah dimana salah satu cabang pada beberapa periode terakhir tidak menyentuh target yang ditetapkan untuk mendapat insentif sehingga PT. Asm Mobil akan mengoptimalkan semua pengeluaran termasuk biaya distribusi material service yang pada kasus ini menggunakan satu produk pelumas mesin yang memiliki tingkat penjualan yang relatif stabil. Pada kasus ini peneliti menggunakan metode Vogel's Approximation Method dan metode stepping stone untuk menghitung biaya optimum secara manual lalu selanjutnya peneliti mengaplikasikan metode stepping stone pada sofware Lingo untuk memverifikasi hasil perhitungan manual tadi supaya didapat hasil yang benar-benar optimal. Perusahaan saat ini menggunakan metode sederhana dengan mengacu pada ongkos terendah tanpa memperhitungkan kuantitas barang yang dikirim sehingga biaya distribusi material yang dikeluarkan saat ini sebesar Rp 5,454,360.00 sedangkan hasil perhitungan menggunakan metode transportasi dan diverifikasi sofware Lingo didapat biaya optimumnya sebesar Rp 5,451,800.00 atau 0,99\% lebih optimum dibanding metode yang dipakai saat ini.
\end{abstract}

Kata kunci: Vogel's Approximation Method, Stepping Stone, Lingo, Optimasi Biaya

\section{Abstract}

PT. Asm Mobil is a company engaged in the service and sales of vehicle service materials which in 2019 established an incentive system to increase productivity in terms of sales so that a problem arises where one of the branches in the last few periods did not touch the target set for incentives so that PT. Asm Mobil will optimize all expenses including material service distribution costs which in this case uses one engine lubricant product that has a relatively stable level of sales. In this case the researchers used the Vogel's Approximation Method and the stepping stone method to calculate the optimum cost manually then the researchers then applied the stepping stone method to the Lingo software to verify the results of the manual calculation in order to obtain truly optimal results. The company currently uses a simple method by referring to the lowest cost without calculating the quantity of goods sent so that the material distribution costs incurred at present amount to $R p$ 5,454,360.00 while the results of calculations using the transportation method and verified Lingo software obtained an optimum cost of Rp 5,451,800.00 or 0.99\% more optimum compared to the method used today.

Keywords: Vogel's Approximation Method, Stepping Stone, Lingo, Cost Optimization

\section{Pendahuluan}

\subsection{Latar Belakang Masalah}

Pada dasarnya setiap unit usaha yang melibatkan sebuah proses pengadaan didalamnya memerlukan sebuah metode khusus yang akan dipakai dalam mengambil setiap kebijakan pada suatu proses pengadaan baik barang maupun jasa. Proses yang berlangsung akan berbeda-beda tergantung metode dan juga permintaan yang mendasari perhitungan kebijakan yang akan diambil 
unit usaha tersebut. Kebijakan yang diambil tentu harus menguntungkan bagi perusahaan tersebut sehingga memberi surplus yang akan berdampak positif bagi keberlangsungan unit usaha tersebut.

Seperti yang disampaikan di awal bahwa setiap kebijakan akan mempengaruhi terhadap pendapatan unit usaha tersebut sehingga metode yang tepat sangat penting guna mengatasi permasalahan yang mungkin timbul, sehingga PT. ASM Mobil sebagai perusahaan yang bergerak dibidang jasa service dan juga penjualan material service kendaraan yang memiliki empat cabang perusahaan di pulau Jawa memiliki kendala yang mana pada tahun 2019 lalu mulai diberlakukannya sistem insentif yang menuntut setiap cabang aktif dalam penjualan supaya mendapat tambahan penghasilan berupa bonus yang diberikan di akhir periode. Salah satu kriteria penilaian untuk mendapatkan insentif yaitu akumulasi dari jumlah pendapatan yang diperoleh pada periode berjalan harus sesuai dengan target, namun pada beberapa periode setelah diresmikannya sistem insentif salah satu cabang yang menjadi sumber data kami tidak menyentuh target sama sekali sehingga PT. ASM Mobil melakukan pengoptimalan semua pengeluaran termasuk biaya distribusi material service yang pada kasus ini peneliti menggunakan satu produk pelumas mesin yang memiliki tingkat penjualan yang relatif stabil dan akan menjadi bahan penelitian guna meminimalisasi biaya distribusi yang timbul sebagai masukan bagi perusahaan untuk mengurangi biaya distribusinya.

Berdasarkan permasalahan yang dialami PT. ASM Mobil tersebut khususnya di bagian distribusi material service, maka metode yang dipakai pada penelitian ini adalah metode transportasi menggunakan Vogel's Approximation Method untuk mencari solusi layak awal lalu menggunakan metode Stepping stone untuk mencari nilai optimalnya. Sebagai bahan perbandingan untuk memverifikasi data hasil perhitungan, penulis menggunakan sebuah sofware sebagai alat bantu yang didesain sangat luas untuk menyelesaikan permasalahan- permasalahan riset operasi yang bernama LINGO sehingga dengan menggabungkan berbagai metode yang dipakai pada kasus ini diharapkan dapat memperoleh hasil optimasi yang benar-benar optimal sehingga dapat menjadi usulan untuk mengoptimalkan biaya yang dikeluarkan khususnya biaya distribusi material service di PT. ASM Mobil.

Sebelum melakukan perhitungan terlebih dahulu penulis menggambarkan alur distribusi material service di PT. ASM Mobil sebagai berikut:

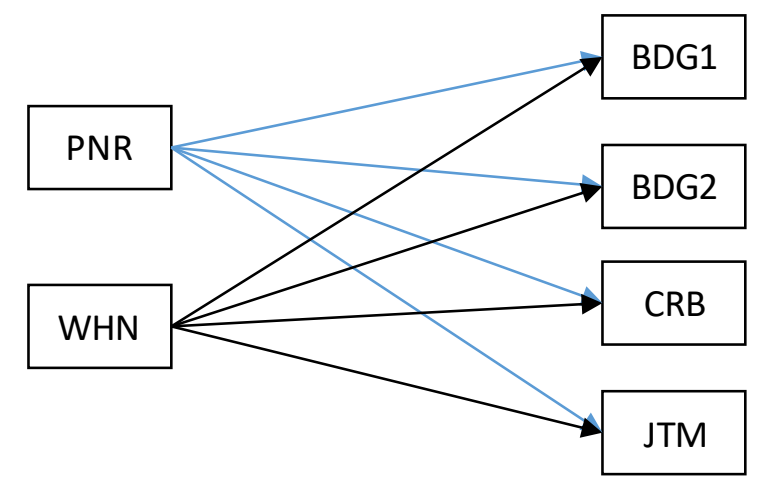

Gambar 1. Alur distribusi material service

PNR dan WHN merupakan distributor material service PT. ASM Mobil yang memasok berbagai kebutuhan material service termasuk pelumas mesin bagi berbagai kendaraan, sedangkan BDG1, BDG2, CRB dan JTM adalah inisial nama dari masing-masing cabang perusahaan PT. ASM Mobil. Pada bulan Januari 2020 total biaya yang dikeluarkan oleh PT. ASM Mobil untuk memenuhi kebutuhan material service khususnya pelumas mesin adalah Rp 5.454.360,00 yang didapat berdasarkan metode sederhana dengan mengambil ongkos terendah tanpa memperhitungkan kuantitas dari barang yang dikirimkan, sehingga biaya tersebut akan diminimalkan kembali pada penelitian ini. 


\subsection{Batasan Penelitian}

a. Jumlah supply pada permasalahan ini dibatasi sampai 1.000 dari 5120 unit.

b. Material yang didistribusikan dibatasi hanya satu jenis material yang memiliki berat satu kilo gram dari total 18 jenis material yang yang ada.

c. Penelitian dilakukan menggunakan data sekunder pada bulan Januari 2020.

\subsection{Asumsi Penelitian}

Biaya yang timbul pada tabel biaya transportasi merupakan biaya untuk satu kilo gram material service sehingga bisa diasumsikan bisa mewakili seluruh material service meskipun jenisnya berbeda.

\section{Tinjauan Pustaka}

\subsection{Distribusi}

Menurut Basu Swastha, definisi distribusi ialah saluran pemasaran yang dipakai oleh pembuat produk untuk mengirimkan produknya ke industri atau konsumen. Lembaga yang terdapat pada saluran distribusi ialah produsen, distributor, konsumen atau industri, sedangkan Komaruddin Sastrodipoera mengemukakan bahwa strategi distribusi dapat didefinisikan dengan beberapa cara, antara lain:

a. Distribusi adalah gerakan barang, dan semua hal termasuk pengertian gerakan, dari pabrik ke pengguna, melalui saluran distribusi.

b. Distribusi mencakup kegiatan yang luas yang berhubungan dengan gerakan produk akhir yang efisien dari ujung garis produksi kepada konsumen.

c. Distribusi berkaitan dengan arus fisik suatu produk dari produsen ke konsumen.

d. Distribusi dalam manajemen meliputi perencanaan, pengorganisasian, pelaksanaan, dan pengawasan arus bahan dan produk akhir dari tempat asal ke tempat pemakai utnuk memenuhi kebutuhan pelanggan dengan mendapatkan laba.

\subsection{Transportasi}

Menurut Salim (2000) Transportasi adalah kegiatan pemindahan barang (muatan) dan penumpang dari suatu tempat ke tempat lain. Dalam transportasi ada dua unsur yang terpenting yaitu pemindahan/pergerakan (movement) dan secara fisik mengubah tempat dari barang (comoditi) dan penumpang ke tempat lain, sedangakan Hasim Purba di dalam bukunya "Hukum Pengangkutan Di Laut" mengatakan bahwa pengangkutan (transportasi) adalah "kegiatan pemindahan orang dan atau barang dari suatu tempat ke tempat lain baik melalui angkutan darat, angkutan perairan maupun angkutan udara dengan menggunakan alat angkutan. Jadi pengangkutan itu berupa suatu wujud kegiatan dengan maksud memindahkan barang-barang atau penumpang (orang) dari tempat asal ke suatu tempat tujuan tertentu."

Metode Transportasi adalah suatu metode yang digunakan untuk mengatur distribusi dari sumber sumber yang menyediakan produk - produk yang sama di tempat- tempat yang membutuhkan secara optimal. Alokasi produk ini harus diatur sedemikian rupa karena terdapat perbedaan biaya transportasi (alokasi) dari suatu sumber ke beberapa tujuan yang berbeda - beda dan dari beberapa sumber ke suatu tujuan juga berbeda - beda (M.A.Yulianto, 2012).

Namun sebelum melakukan uji optimasi, harus terlebih dahulu menentukan solusi awal dengan salah satu metode yaitu north west corner, least cost atau Vogel's Approximation Method baru selanjutnya mencari solusi optimalnya. Pada studi kasus ini penulis akan menggunakan Metode Vogel's Approximation Method sebagai solusi layak awal dan metode Stepping Stone untuk mencari nilai optimalnya.

a. Vogel's Approximation Method

Menurut Siswanto (2006, p279), Langkah-langkah metode VAM dapat diringkas sebagai berikut:

1) Buatlah matrik yang menunjukkan kebutuhan masing-masing sumber dan biaya transportasi per unit. 
2) Carilah selisih antara dua biaya terkecil di masing-masing kolom baris.

3) Pilih selisih terbesar di antara selisih-selisih yang telah dihitung pada langkah pertama.

4) Sesuaikan penawaran dan permintaan untuk menunjukkan alokasi yang sudah dilakukan.

5) Hilangkan semua baris dan kolom dimana penawaran dan permintaan telah dihabiskan.

6) Jika semua penawaran dan permintaan belum dipenuhi, kembali ke langkah 1, jika semua penawaran dan permintaan solusi awal diperoleh.

b. Metode Stepping Stone

Stepping Stone adalah suatu teknik yang berulang untuk berpindah dari suatu solusi awal yang layak ke solusi yang optimal dalam metode transportasi. Setelah solusi layak dasar awal diperoleh dari masalah transportasi ,langkah berikutnya adalah menekan kebawah biaya transportasi dengan memasukkan variabel non basis (yaitu alokasi barang ke kotak kosong) ke dalam solusi. Proses evaluasi variabel yang memungkinkan terjadinya perbaikan solusi dan kemudian mengalokasikan kembali dinamakan metode stepping stone.

Secara umum persamaanya adalah sebagai berikut:

Fungsi tujuan :

$$
\text { Minimum } Z=\sum_{j=1}^{m} \sum_{i=1}^{n} C_{i j} X_{i j}
$$

Dengan Batasan:

$\sum_{j=1}^{m} X_{i j}=A_{i} ; i=1,2, \ldots n$

$\sum_{i=1}^{n} X_{i j}=B_{j} ; j=1,2, \ldots m$

$C i j=$ biaya transportasi per unit barang dari sumber $i$ ke tujuan $j$

$X i j=$ jumlah barang yang didistribusikan dari sumber $i$ ke tujuan $j$

$A i .=$ jumlah barang yang ditawarkan atau kapasitas dari sumber $i$

$B j=$ jumlah barang yang diminta atau dipesan oleh tujuan $j$

$m=$ banyaknya sumber

$n=$ banyaknya tujuan

c. Lingo

Lingo adalah alat bantu yang didesain sangat luas untuk menyelesaikan permasalahanpermasalahan riset operasi seperti program linier dan non linier, kuadratik, quadratically constrained, stokastik dan optimasi model integer dengan lebih cepat, mudah dan efisien. Lingo menyediakan paket integrasi lengkap yang termasuk di dalamnya yaitu bahasa untuk optimasi model yang mudah dipahami. 


\section{Pembahasan}

\subsection{Metodologi Penelitian}

Bagan metodologi penelitian ditunjukkan pada Gambar 2:

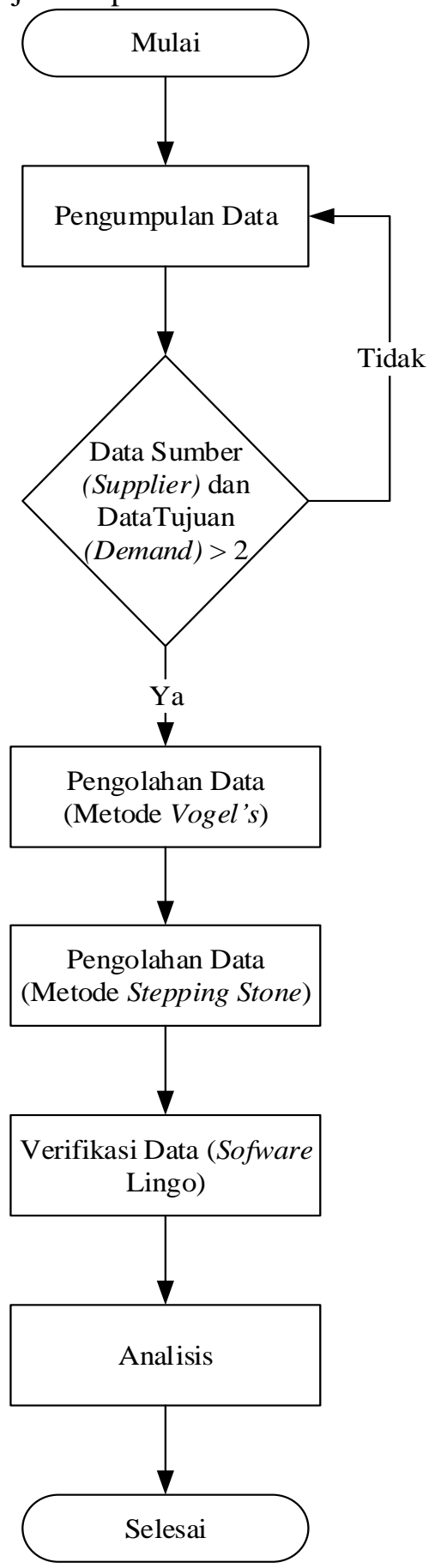

Gambar 2. Metodologi penelitian 


\subsection{Pengumpulan Data}

Data yang dikumpulkan berdasarkan survei di lapangan mengenai biaya dan jumlah pelumas mesin yang dikirimkan pada satu kali pengiriman. Berikut data awal yang penulis dapatkan.

Tabel.1 Biaya Distribusi

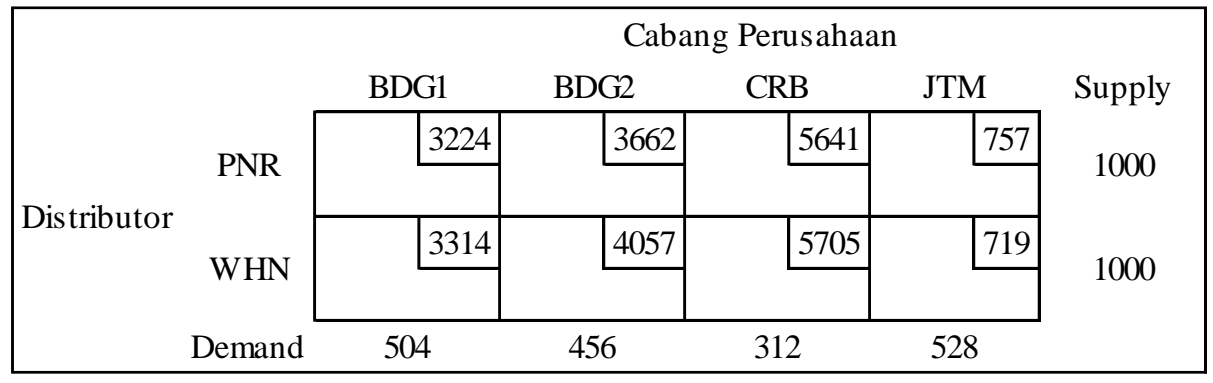

Data Tabel 1 menunjukkan bahwa total supply sebanyak 2000 kilo sedangkan jumlah demand sebanyak 1800 kilo. Antara demand dan supply harus seimbang agar proses perhitungan dapat berjalan dengan demikian dibutuhkan sebuah variabel dummy sebagai pelengkap guna menyeimbangkan kedua data tersebut.

\subsection{Pengolahan data}

Dengan menggunakan metode Vogel dalam mencari solusi layak awal didapatlah bahwa jumlah pengiriman yang optimal menurut metode Vogel adalah sebagai berikut:

Tabel.2 Solusi layak dengan metode vogel

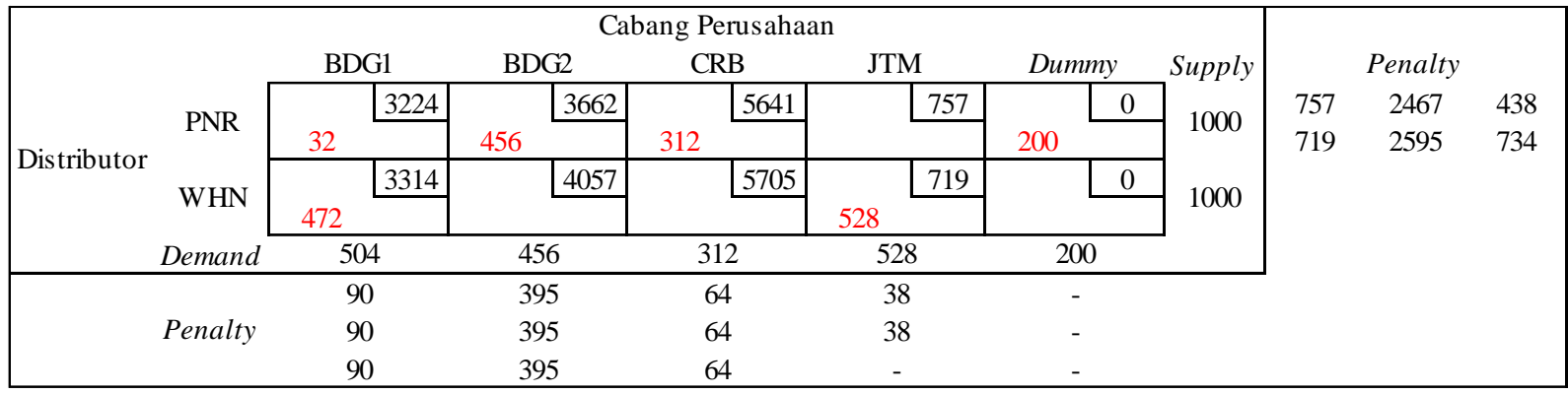

Pada solusi awal dengan metode vogel didapat biaya awalnya adalah sebagai berikut:

$=(32 \times 3224)+(456 \times 3662)+(312 \times 5641)+(0 \times 757)+(200 \times 0)+(472 \times 3314)+(0 \times 4057)+$ $(0 \times 5705)+(528 \times 719)+(0 \times 0)$

$=\operatorname{Rp} 5.476 .872,00$.

Sehingga solusi awalnya adalah sebagai berikut:

Tabel.3 Ringkasan hasil solusi awal dengan metode vogel

\begin{tabular}{|c|c|c|}
\hline Distributor & Cabang Perusahaan & Jumlah Material \\
\hline \multirow{4}{*}{ PNR } & BDG1 & 32 \\
\cline { 2 - 3 } & BDG2 & 456 \\
\cline { 2 - 3 } & CRB & 312 \\
\cline { 2 - 3 } & Dummy & 200 \\
\hline \multirow{2}{*}{ WHN } & BDG1 & 472 \\
\cline { 2 - 3 } & JTM & 528 \\
\hline \multicolumn{2}{|c|}{ Total } & 2000 \\
\hline
\end{tabular}

Dari hasil perhitungan vogel tentu saja belum dikatakan optimal bila tidak dilakukan perhitungan selanjutnya yaitu mencari nilai optimalnya menggunakan metode stepping stone. 
Tabel.4 Solusi optimal dengan metode stepping stone

\begin{tabular}{|c|c|c|c|c|c|c|c|c|c|}
\hline \multirow{7}{*}{ Distributo } & \multicolumn{9}{|c|}{ Cabang Perusahaan } \\
\hline & & \multicolumn{2}{|c|}{ BDG1 } & BDG2 & CRB & JTM & \multicolumn{2}{|c|}{ Dummy } & \multirow{3}{*}{$\begin{array}{c}\text { Supply } \\
1000\end{array}$} \\
\hline & \multirow{2}{*}{ PNR } & & 3224 & \begin{tabular}{|l|l|}
3662 \\
\end{tabular} & \begin{tabular}{|l|l|}
5641 \\
\end{tabular} & \begin{tabular}{l|l|}
757 \\
\end{tabular} & & 0 & \\
\hline & & 504 & & 456 & 40 & & & & \\
\hline & \multirow{2}{*}{ WHN } & & 3314 & 4057 & 5705 & 719 & & 0 & \multirow{3}{*}{1000} \\
\hline & & & & & 272 & 528 & \multicolumn{2}{|l|}{200} & \\
\hline & Demand & & & 456 & 312 & 528 & & & \\
\hline
\end{tabular}

Pada solusi optimal dengan metode Stepping stone didapat biaya distribusinya adalah sebagai berikut:

$$
\begin{aligned}
= & (504 \times 3224)+(456 \times 3662)+(40 \times 5641)+(0 \times 757)+(0 \times 0)+(0 \times 3314)+(0 \times 4057)+(272 \times 5705) \\
& +(528 \times 719)+(200 \times 0) \\
= & \text { Rp 5.451.800,00. }
\end{aligned}
$$

Dari Tabel 4 diperoleh solusi optimal dengan metode stepping stone adalah sebagai berikut:

Tabel.5 Ringkasan hasil optimal dengan metode stepping stone

\begin{tabular}{|c|c|c|}
\hline Distributor & Cabang Perusahaan & Jumlah Material \\
\hline \multirow{3}{*}{ PNR } & BDG1 & 504 \\
\cline { 2 - 3 } & BDG2 & 456 \\
\cline { 2 - 3 } & CRB & 40 \\
\hline \multirow{3}{*}{ WHN } & Dummy & 200 \\
\cline { 2 - 3 } & CRB & 272 \\
\cline { 2 - 3 } & JTM & 528 \\
\hline \multicolumn{2}{|c|}{ Total } & 2000 \\
\hline
\end{tabular}

Dengan demikian setelah dilakukan perhitungan dengan menggunakan metode stepping stone, didapat bahwa solusi awal dengan menggunakan metode vogel belum mendapat nilai optimalnya ini dikarenakan metode vogel pada tiap iterasinya menggunakan nilai penalty yang mana dari tiap poin penalti yang diberikan akan mempengaruhi posisi dari tiap nilai pada demand yang ditempatkan di masing-masing cabang sehingga jika kebutuhan dari satu cabang belum terpenuhi maka akan mengambil nilai demand dari posisi terdekatnya yang akan menyebabkan ongkos yang dihasilkan semakin besar yaitu senilai Rp 5.476.872,00. Berbeda dengan metode Stepping stone yang menggunakan loncatan dari satu titik cabang ke titik yang lain guna mendapat nilai terendah tanpa mengubah volume dari tiap cabang sehingga hampir semua titik cabang telah diuji satu demi satu untuk mendapat nilai terendah dari tiap ongkos yang dihasilkan sehingga metode stepping stone dikatakan optimal karena menghasilkan biaya distribusi terendah yaitu sebesar $\mathrm{Rp}$ 5.451.800,00 atau 0,99\% lebih rendah dari perhitungan vogel.

Namun perhitungan yang dilakukan dengan metode stepping stone belum sepenuhnya dapat di anggap benar tanpa verifikasi hasil pengolahan data yang dihasilkan, karenanya model matematis metode stepping stone diaplikasikan pada sofware lingo untuk menguji hasil yang didapat dari perhitungan metode stepping stone apakah sudah benar-benar optimal atau tidak, dengan demikian bilamana hasilnya sama berari perhitungan yang dilakukan sudah benar dan hasil sudah benarbenar optimal dan dapat dikatakan valid. Berikut data hasil perhitungan yang dilakukan menggunakan sofwate lingo: 


\begin{tabular}{|c|c|c|}
\hline $\begin{array}{l}\text { Objective value: } \\
\text { Infeasibilities: } \\
\text { Total solver iterations: }\end{array}$ & \multicolumn{2}{|c|}{$\begin{array}{l}5451800 . \\
0.000000\end{array}$} \\
\hline Variable & Value & Reduced Cost \\
\hline SUPPLY ( S1) & 1000.000 & 0.000000 \\
\hline SUPPLY ( S2) & 1000.000 & 0.000000 \\
\hline DEMAND ( BDG1) & 504.0000 & 0.000000 \\
\hline DEMAND ( BDG2) & 456.0000 & 0.000000 \\
\hline DEMAND ( CRB) & 312.0000 & 0.000000 \\
\hline DEMAND ( JTM) & 528.0000 & 0.000000 \\
\hline $\operatorname{cosT}(\mathrm{S} 1, \mathrm{BDG} 1)$ & 3224.000 & 0.000000 \\
\hline $\operatorname{cosT}(\mathrm{S1}, \mathrm{BDG} 2)$ & 3662.000 & 0.000000 \\
\hline $\cos T(\mathrm{~S} 1, \mathrm{CRB})$ & 5641.000 & 0.000000 \\
\hline $\operatorname{cosT}(\mathrm{S} 1, \mathrm{JTM})$ & 757.0000 & 0.000000 \\
\hline $\operatorname{cosT}(\mathrm{S} 2, \mathrm{BDG} 1)$ & 3314.000 & 0.000000 \\
\hline $\operatorname{cosT}(\mathrm{S} 2, \mathrm{BDG} 2)$ & 4057.000 & 0.000000 \\
\hline $\operatorname{cosi}(\mathrm{S} 2, \mathrm{CRB})$ & 5705.000 & 0.000000 \\
\hline $\operatorname{cosT}(\mathrm{S} 2, \mathrm{JTM})$ & 719.0000 & 0.000000 \\
\hline VALUE ( $S 1$, BDG1) & 504.0000 & 0.000000 \\
\hline VALUE ( S1, BDG2) & 456.0000 & 0.000000 \\
\hline VALUE ( $S 1, C R B)$ & 40.00000 & 0.000000 \\
\hline VALUE ( S2, CRB) & 272.0000 & 0.000000 \\
\hline VALUE ( S2, JTM) & 528.0000 & 0.000000 \\
\hline Row & Slack or Surplus & Dual Price \\
\hline 2 & 0.000000 & -3288.000 \\
\hline 3 & 0.000000 & -3726.000 \\
\hline 4 & 0.000000 & -5705.000 \\
\hline 5 & 0.000000 & -719.0000 \\
\hline 6 & 0.000000 & 64.00000 \\
\hline
\end{tabular}

Gambar 3. Hasil perhitungan menggunakan sofware lingo

Dari hasil perhitungan sofware lingo didapat biaya total untuk distribusi material pelumas adalah sebesar Rp 5.451.800,00 dengan alokasi yang dihasilkan sebagai berikut:

Tabel 6. Ringkasan hasil optimal sofware lingo

\begin{tabular}{|c|c|c|}
\hline Distributor & Cabang Perusahaan & Jumlah Material \\
\hline \multirow{3}{*}{ PNR } & BDG1 & 504 \\
\cline { 2 - 3 } & BDG2 & 456 \\
\cline { 2 - 3 } & CRB & 40 \\
\hline \multirow{2}{*}{ WHN } & CRB & 272 \\
\cline { 2 - 3 } & JTM & 528 \\
\hline \multicolumn{2}{|c|}{ Total } & 1800 \\
\hline
\end{tabular}

Dengan demikian perhitungan metode stepping stone yang dilakukan sudah benar dengan hasil yang benar-benar optimal yaitu sebesar Rp 5.451.800,00. 


\section{Kesimpulan Dan Saran \\ 4.1 Kesimpulan}

Setelah melakukan penelitian tentang pengaplikasian metode steping stone pada sofware lingo untuk mecari optimasi biaya pada studi kasus PT. ASM Mobil peneliti menyimpulkan hasil penelitian sebagai berikut:

a. Untuk mencari biaya distribusi yang optimal saat ini perusahaan tidak melakukan pendekatan dengan metode apa pun sehingga penulis mengusulkan untuk menggunakan salah satu metode transportasi yaitu vogel atau stepping stone.

b. Penerapan metode usulan baik vogel atau stepping stone akan berdampak positif bagi perusahaan yang mana perusahaan akan mendapatkan optimasi biaya distribusi yang lebih optimal jika dibanding dengan metode yang saat ini dipakai, sehingga dengan optimalnya biaya distribusi tersebut juga akan berdampak pada perusahaan keseluruhan yang mana jika semua kebutuhan perusahaan khususnya material service yang didistribusikan diperhitungkan secara matang menggunakan metode usulan tersebut bukan tidak mungkin akan mendongkrak pendapatan perusahaan dengan optimasi biaya distribusi yang dilakukan.

c. Dengan metode stepping stone bisa dijadikan acuan untuk mendapat nilai paling optimal dikarenakan pada metode stepping stone setiap titik dari tiap cabang di uji keoptimalannya yang tentu saja jika tiap titik di uji maka akan menghasilkan nilai yang paling rendah jika kasusnya minimasi namun kekurangannya pada metode ini adalah membutuhkan iterasi yang cukup panjang untuk menyelesaikan satu persoalan yang mana dari tiap iterasi proses pengujian berlangsung terus menerus sampai mendapat titik optimalnya sehingga metode ini akan memerlukan waktu yang cukup panjang jika jumlah data yang didapat juga semakin banyak.

d. Pada saat menggunakan sofware lingo sebagai alat bantu hitung terlebih dahulu harus memahami persamaan yang dipakai pada metode transportasi dan juga memahami setidaknya standar penulisan atau bahasa pemrograman yang dipakai di sofware lingo sehingga dalam pengaplikasian metode transportasi bisa langsung mengubah persamaan menjadi bahasa pemrograman.

e. Sofware lingo dirasa sangat praktis dalam mencari nilai optimal namun kesulitannya adalah menerjemahkan model matematis ke bahasa pemrograman yang dipakai oleh lingo perlu latihan khusus juga pemahaman mendalam agar dapat menggunakan sofware ini.

\subsection{Saran}

Dari kesimpulan di atas , Penulis memiliki beberapa saran di antaranya:

a. Sebaiknya perusahaan memiliki metode perhitungan khusus dalam melakukan distrbusi barang tidak hanya melihat dari satu sisi seperti ongkos kirim saja tetapi juga kuantitas barang yang dikirimkan juga termasuk hal yang harus diperhitungkan juga.

b. Untuk mencari nilai yang benar-benar optimal sebaiknya tidak terpaku pada satu metode saja tetapi gunakan metode-metode lainya agar mendapat hasil yang benar-benar optimal.

c. Jika data yang dipakai lebih banyak sebaiknya menggunakan metode norwesh corner untuk mendapatkan solusi layak awal sehingga akan mempersingkat waktu perhitungan.

d. Dalam mencari solusi pada kasus riil diperlukan beberapa asumsi untuk menutupi kekurangan data sehingga dalam menentukan nilai suatu asumsi penulis menyarankan untuk mengambil data pada perusahaan yang bergerak dibidang yang sama guna mendapat nilai yang mendekati sebenarnya. 


\section{Daftar Pustaka}

Ali, N. P. H., (2013), Aplikasi Metode Stepping Stone Untuk Optimasi Perencanaan Biaya Pada Suatu Proyek Konstruksi ( Studi Kasus : Proyek Pemeliharaan Ruas Jalan Di Senduk, Tinoor, dan Ratahan), Jurnal Sipil Statik Vol. 1 No. 8, Juli 2013 (571-578), ISSN: 2337-6732.

Aminunudin, (2005), Prinsip-Prinsip Riset Operasi, Penerbit Erlangga, Jakarta.

Christina, et al., (1998), "Pengaplikasian Metode Stepping Sotone di Perusahaan Air Minum di Bandung", Proceedings of the $1^{\text {st }}$ National Industrial Engineering Conference, 20-22 Februari, Surabaya, pp. A301-A312.

M. A. Yulianto, (12 September 2012). Metode transportasi. Diakses pada 12 Januari 2020, dari https://digensia.wordpress.com/2012/03/.

Mulyono, Sri, (2002), Riset Operasi. Jakarta: Penerbit Fakultas Ekonomi UI.

N. M. A. Pranati, (2018), Optimalisasi Biaya Transportasi Pendistribusian Keramik Menggunakan Model Transportasi Metode Stepping Stone (Studi Kasus: Pt. Indah Bangunan), Jurnal Ilmiah Matematika Dan Terapan Volume 15 Nomor 1 Juni 2018 (Halaman 48 - 57), ISSN : 2450 - 766X.

Nyoman Martha Adiwikanta, Ni Ketut Kertiasih, (2013), Optimalisasi Pemecahan Masalah Transportasi Menggunakan Metode Nwc, Inpeksi, Dan Vam, Jurnal Ilmiah Matematika, Vol. 10, No. 2, ISSN 0216-3241.

Purba Hasim, (2006), Hukum Pengangkutan di Laut, Penerbit Sinar Grafika, Jakarta.

Salim Abbas, (2000), Menejemen Transportasi, Penerbit Rajagrafindo Persada, Depok.

Siswanto, (2006), Operation Research Jilid 1, Penerbit Erlangga, Jakarta.

Swastha Basu, (2005), Menejemen Pemasaran Modern, Penerbit Liberty, Yogyakarta. 